\title{
Congenital tumours of the anterior visual system with dysplasia of the optic discs
}

\author{
DAVID TAYLOR \\ From the Hospital for Sick Children, Great Ormond Street, and the National Hospitals for Nervous Diseases, \\ Queen Square, London WC1
}

SUMmARY The occurrence of dysplastic optic discs in young patients with tumours involving the anterior visual pathway not only may provide a valuable diagnostic sign but also bears witness to the early prenatal origin of these tumours.

An optic disc may be considered to be dysplastic when it is congenitally abnormal owing to a developmental abnormality. Gross anomalies include colobomata and pits, and the optic disc may be of abnormal size, an unusual shape, or have an abnormal vascular arrangement. Minor developmental anomalies include unusual pigmentation or abnormalities of the peripapillary retina. Small dysplastic or hypoplastic discs may be difficult to diagnose, since there are no absolute criteria and no readily available techniques for measurement. Clinical judgment can be enhanced by evaluation of the ratio between the apparent size of the disc and the retinal arterioles or the size of a disc relative to the size of the fundus in a standard fundus photograph, but even with these techniques the vagaries of observation leave the diagnosis to the clinician alone. Anomalies of the outline and vasculature have to be obvious to be considered abnormal, but there are no definitive criteria. The incidence of congenital optic disc anomalies in the population is impossible to assess, but Duke-Elder ${ }^{1}$ considered them to be rare in their gross forms, and Riise ${ }^{2}$ estimated that a common type of optic disc anomaly, the inferonasal conus, occurs in $1 \%$ of the population.

Congenitally abnormal optic discs have been reported with bitemporal visual field defects, unassociated with disease of the nervous system, ${ }^{2-5}$ suggesting a concomitant chiasmal anomaly. Anomalous optic discs in patients with suprasellar tumours have been considered ${ }^{2467}$ to be an incidental association. These authors reported 6 cases, and of the 2 patients in whom the pathology was recorded one had a dysgerminoma and clearly congenitally

Correspondence to Dr D. Taylor, Eye Department, Hospital for Sick Children, Great Ormond Street, London WC1. abnormal discs, and the other had a pituitary adenoma and an abnormal optic disc on one side. The latter patient was aged 19, and it is interesting that only $2.4 \%$ of 1000 chromophobe adenomas in the Mayo Clinic series ${ }^{8}$ were below 20 years old. Keane ${ }^{6}$ also pointed out that this patient had a monocular hemianopic scotoma, found only in $2 \%$ of the Mayo Clinic series. The monocular hemianopic scotoma was in the eye with the abnormal optic disc-clearly an unusual case. Keane ${ }^{6}$ points out that the relationship of the visual field defect to the midline and a careful fundus examination will distinguish clinically between the cases with chiasmal compression and those with an isolated dysplastic optic disc.

This paper describes 7 children with dysplastic optic discs associated with a suprasellar tumour of presumed prenatal origin, and suggests a causal relationship. These cases form part of a series of 23 patients presented previously. ${ }^{9}$ Most of the patients had complicated histories, so that details relating to the visual system and the diagnosis only will be included.

\section{Case histories}

CASE 1

A girl born in April 1966 was well until December 1973, when her parents noticed bulging of her left eye. In January 1974 she had an acuity of 6/6 right eye and $6 / 12$ left eye (plano right eye -0.75 cyl $170^{\circ}$ left eye). By June 1974 the acuity of the left eye had deteriorated to $6 / 24$, and a mildly swollen left optic disc was noted. She had an enlarged optic canal on the left. Cosmetic left medial rectus surgery and an optic nerve biopsy were performed at another hospital. The histological examination showed a low-grade 
Fig. 1 Case 1. The fundi in October 1977. The right optic disc is normal but the left is segmentally hypoplastic or tilted. There was a glioma of the left optic nerve.
Fig. 2a Case 2. The fundi in May 1976. There was a glioma of the chiasm and left optic nerve. The left disc was small and tilted, with shunt vessels. The right disc was substantially normal, but the presence of a temporal hemianopia is suggested by the presence of a horizontal band of relative optic atrophy.
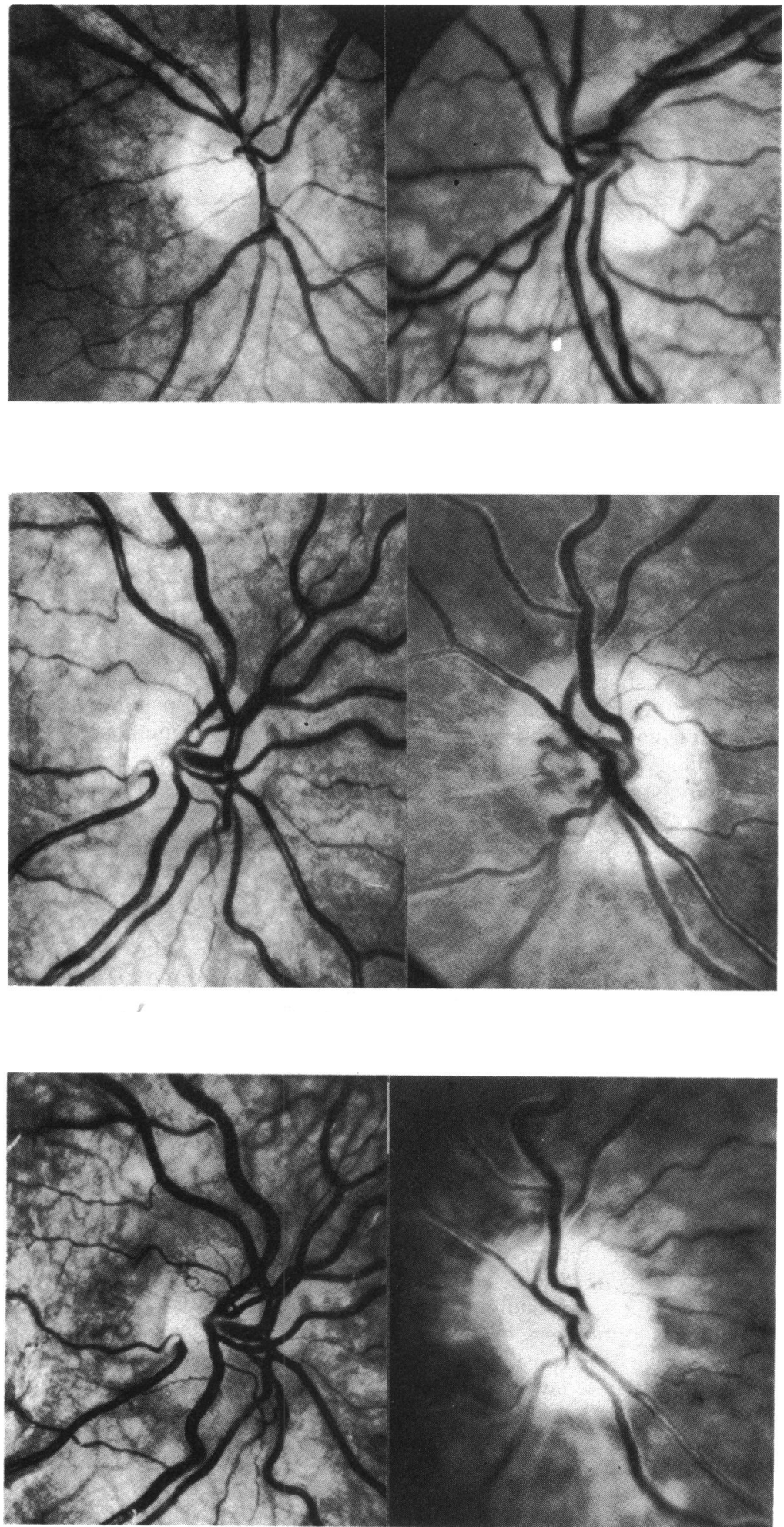

Fig. 2b Case 2. The fundi in January 1978. The left disc is now totally atrophic but still tilted, while the right shows a bilobulated papilloedema that corresponds to the intact nerve fibres subserving the nasal visual field. 


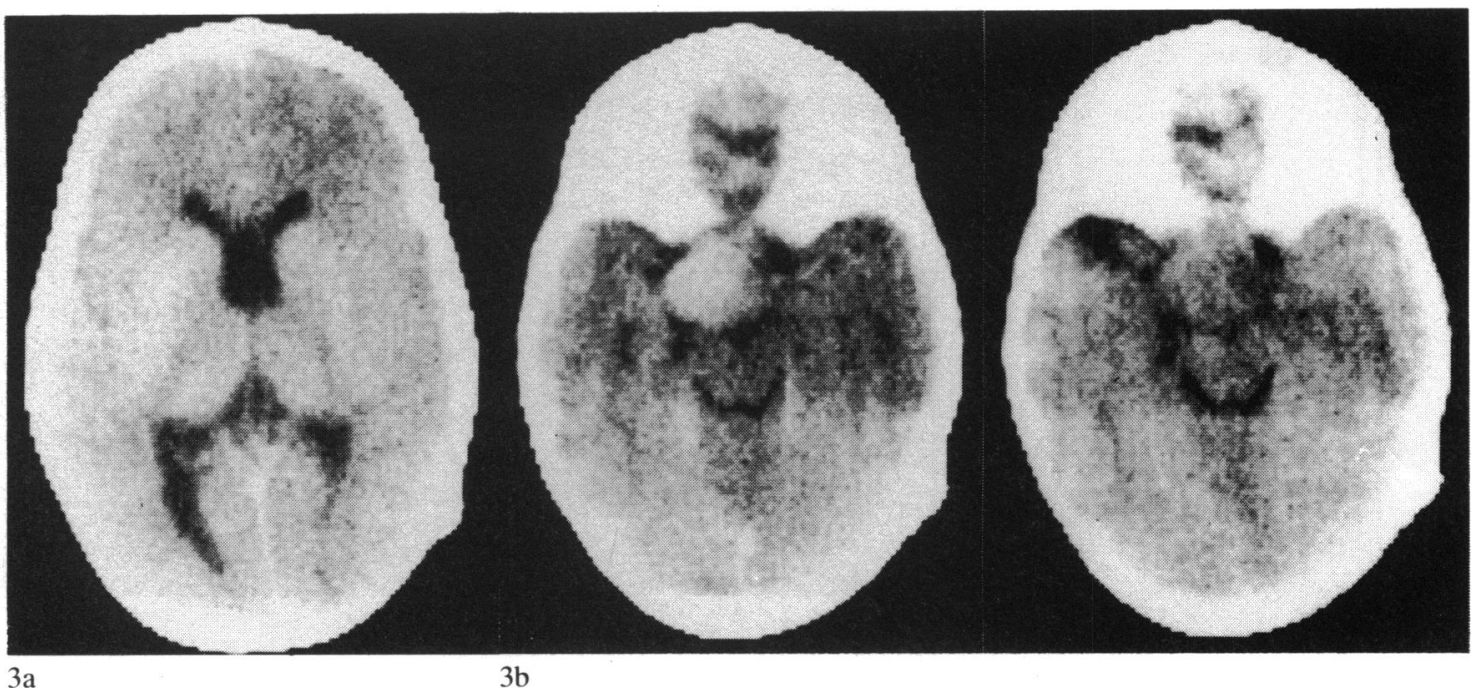

Fig. 3a Case 3. CT scan through the ventricles showing absence of the septum pellucidum.

Fig. 3b Case 3. CT scan through the suprasellar cistern shows a small mass towards the left hand side. On the left is the scan after enhancement, demonstrating its vascularity. A biopsy was not carried out owing to the child's stable condition since infancy.

glioma. In April 1975 the left acuity was 4/60, improving to $6 / 60$ with correction $\left(+7 \cdot 50\right.$ cyl $\left.90^{\circ}\right)$. She had gross proptosis and the left optic disc was seen to be pale and tilted (Fig. 1). The optic nerve was subsequently removed by a combined orbital and subfrontal approach.

CASE 2

A girl born in April 1968 had developed a squint by 1973 , which ultimately led to the diagnosis of a suprasellar and left optic nerve tumour, proved on biopsy to be pilocytic astrocytoma.

The left eye had had very poor vision since she was first seen and in 1976 . The acuity was $4 / 60$ unaided, and shunt vessels were noted on the small, tilted disc (Fig. 2a). There was no refractive error. From 1974 she had a gradually increasing temporal visual field defect in the right eye, and by 1977 this was absolute. In 1978 she had an episode of raised intracranial pressure which gave the appearance of twin peaks of papilloedema in the right eye, while the left optic nerve showed 'total' atrophy and loss of nerve fibres (Fig. 2b). She became blind at that time but regained some vision after a shunt operation.

\section{CASE 3}

In 1979 this 6-year-old girl of Portugese extraction was seen by Mr M. D. Sanders, of the National Hospital, Queen Square.

The limited history available was that her parents noticed her vision was reduced when she was 2 months old, but she seemed to see enough to follow objects. When she was 5 months old she had 2 ventricular shunts for hydrocephalus. At 5 years old she was noted to have very poor vision in the right eye and limited vision in the left eye. She had no other symptoms. On examination she was just able to identify objects with the right eye but had $6 / 60$ acuity in the left; the visual fields were grossly constricted. Both optic discs were obviously hypoplastic, the right one having a figure of 8 outline (Fig. 3c). A CT brain scan showed absence of the septum pellucidum (Fig. 3a) and a suprasellar mass (Fig. 3b). No further treatment or biopsy was performed.

CASE 4

This boy was born in 1958 and his early life was uneventful.

In 1975 he was investigated for short stature and delayed puberty and suprasellar calcification was shown. In 1977 his vision deteriorated and he had headaches. His corrected acuity was $6 / 5$ right eye $(-4.0$ sphere $)$ and $6 / 4$ left eye $(-4 \cdot 50$ sphere $)$. He had a bitemporal hemianopia. Bilaterally hypoplastic and tilted discs were noted (Fig. 4). A clinical diagnosis of craniopharyngioma was made, and this was subsequently confirmed by histopathology when subtotal excision was performed, followed by radiotherapy.

CASE 5

This girl was born in March 1970 and was noted at 
Fig. 3c Case 3. Both optic discs are hypoplastic, and that on the right has a figure of 8 outline, suggesting that there may have been a congenital temporal hemianopia.
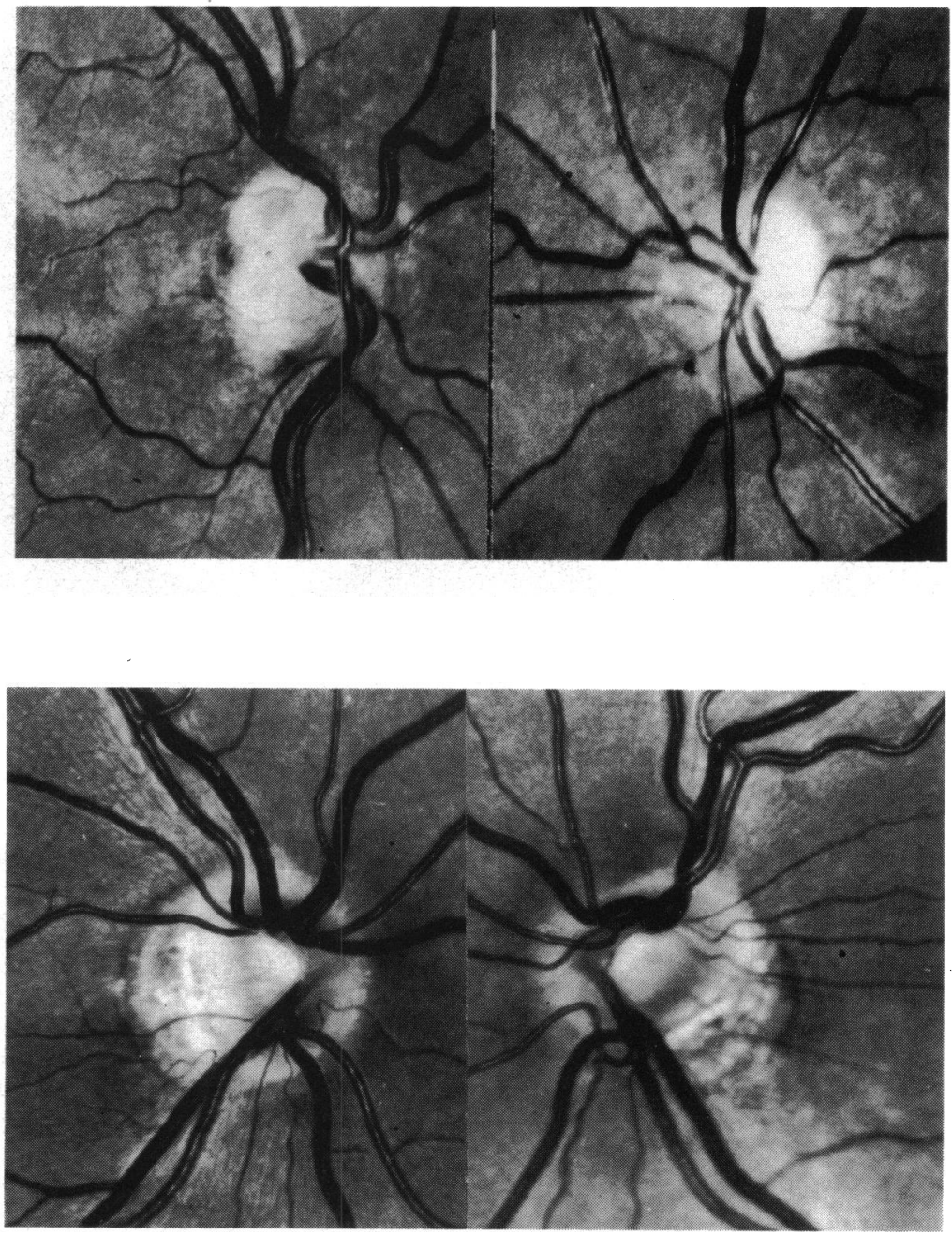

Fig. 4 Case 4. The fundi in April 1977 now had bilaterally tilted optic discs, especially on the left side, which was significantly hypoplastic. The patient had a craniopharyngioma.

Fig. 5 Case 5. The fundi in December 1977 showed gross optic atrophy and thinning of the retinal nerve fibre layer. The left optic disc was oval and somewhat irregular in outline. The patient had a chiasmal glioma.

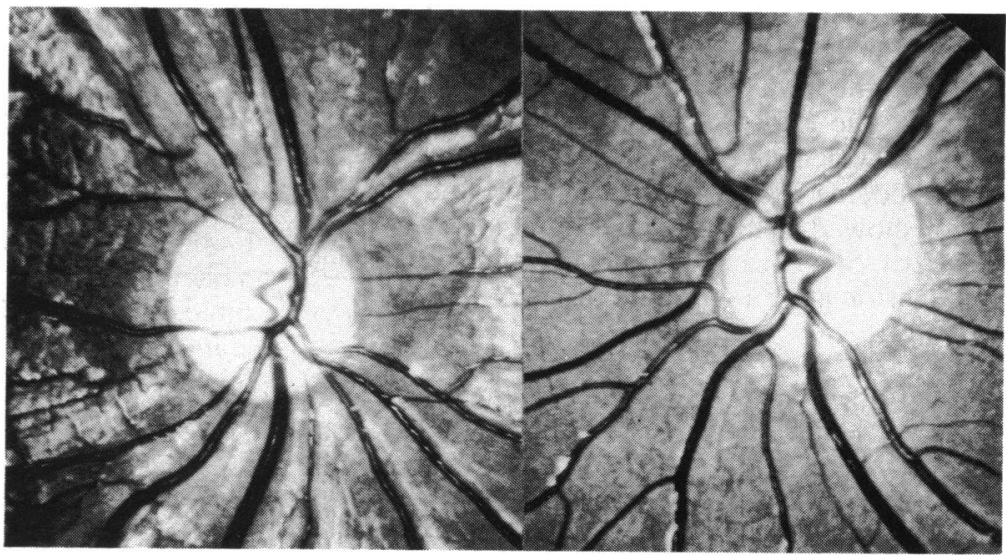




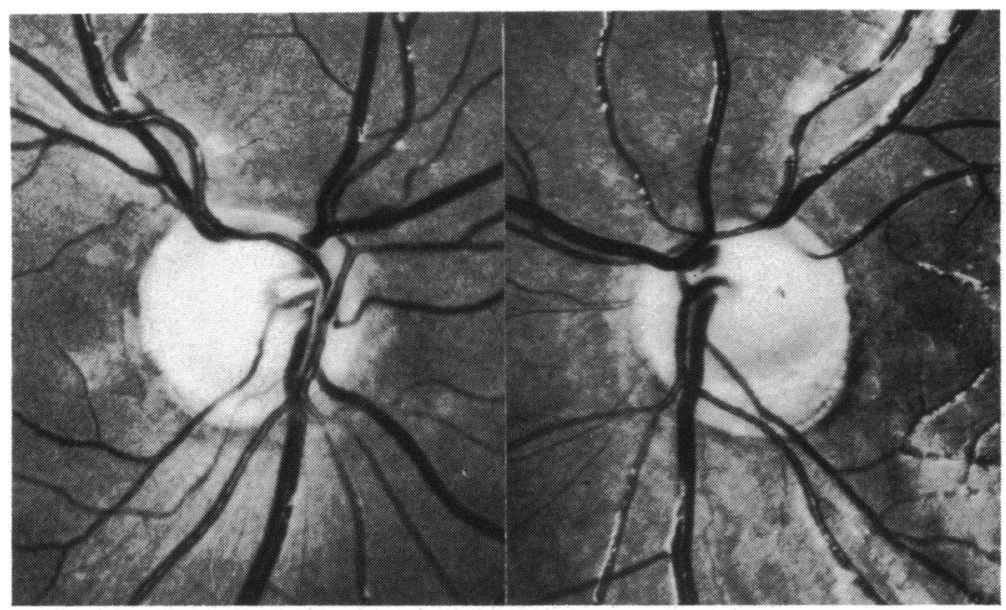

Fig. 6a Case 6. The fundi in March 1975 show that both discs are pale and both abnormal in outline, the left being definitely segmentally hypoplastic or tilted. In the right eye it is possible to see clearly the presence of some nerve fibres above and below the optic disc. She had a bitemporal hemianopia.

birth to have dermatological signs of von Recklinghausen's disease. In 1977 her vision was found to be defective at school, and in December 1977 at the Hospital for Sick Children, Great Ormond Street, she had an acuity of $3 / 36$ in the right eye and $3 / 60$ in the left. There was no refractive error. A bitemporal hemianopia was noted. A CT brain scan showed a suprasellar mass, and both her discs were atrophic, with the left disc having an oval, irregular outline (Fig. 5). She was ultimately transferred to another hospital and had a biopsy, which showed a fibrillary astrocytoma.

CASE 6

This girl was born in October 1964 and suffered no symptoms until she was 10 years old, when she suddenly lost vision. The cause of this was found to be a craniopharyngioma, which was histologically confirmed on several occasions. She had several operations and a course of radio-therapy. In 1975 she had a bitemporal hemianopia and acuities of 6/36 right eye and 6/8 left eye with no refractive error. Bilateral tilted discs were noted (Fig. 6a). In July 1978 she became drowsy and was found to have papilloedema (Fig. 6b), which on fluorescein angiography of the right eye was seen to be of bilobular appearance (Fig. $6 c)$; both optic discs were atrophic and tilted. After a shunt operation her symptoms improved, but after further surgery on 21 July 1978 for gross enlargement of a cystic space she became totally blind, with no pupil reaction to light. She remained blind until October 1979, when she stated that she could see better than before; she had had a profound religious experience some months previously. On examination

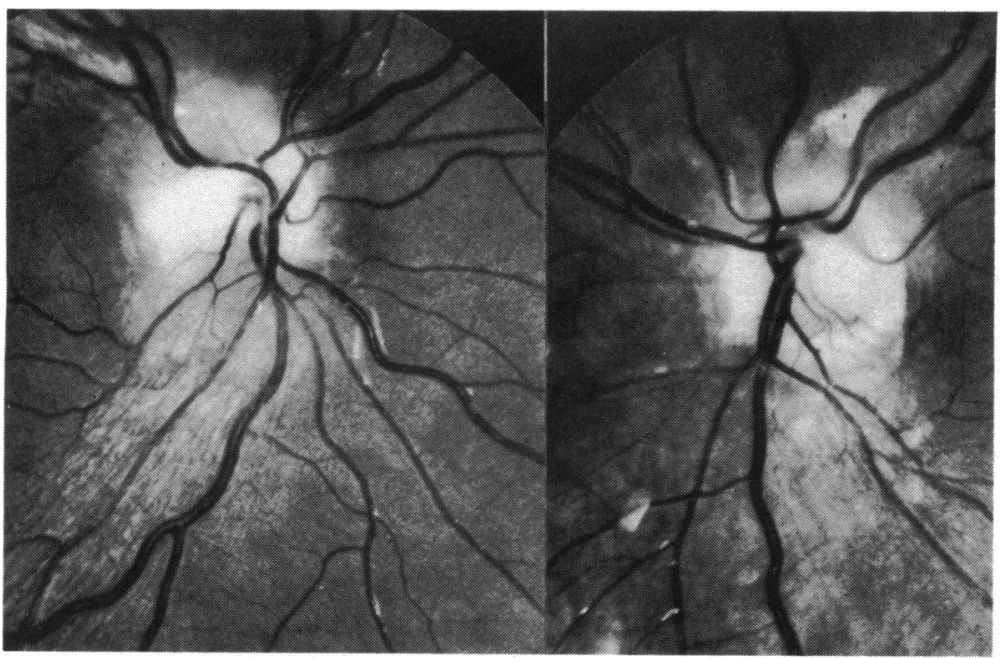

Fig. 6b Case 6. The fundi in July 1978 show bilateral swelling of the remaining nerve fibres of the upper and lower poles due to raised intracranial pressure. 


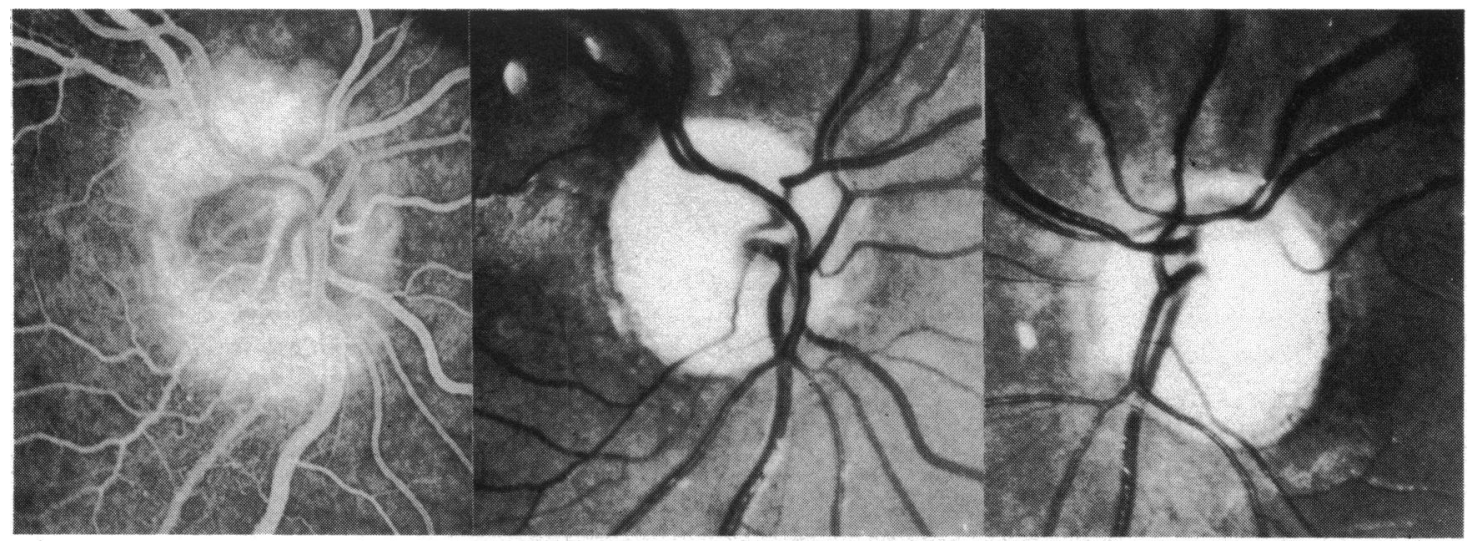

Fig. 6c Case 6. A fluorescein angiogram of the right optic disc in July 1978 showed dilatation of the peripapillary capillary plexus and leakage of fluorescein of the upper and lower poles, which are the areas corresponding to the insertion of intact retinal nerve fibres from the area subserving the nasal half field.

Fig. 6d Case 6. The fundi in October 1979. Although the patient appears to have total optic atrophy and at this time had no perception of light, she later regained 6/12 acuity in the right eye, with an extremely small visual field.

in July 1981 she was able to see $6 / 12$ with the right eye $\left(\frac{-2 \cdot 0}{-0 \cdot 50180}\right)$ but had no perception of light with the left eye $\left(\frac{-0 \cdot 50}{-}\right.$ retinoscopy). She was able to read $6 / 9$ near equivalent. Her remaining visual field was so small as to be of little value to her in moving about. Both discs were grossly atrophic and tilted.

\section{CASE 7}

This 32-year-old man of Middle Eastern extraction was seen on one occasion in June 1981. He had von Recklinghausen's disease and a tumour involving the suprasellar cystern and the left optic nerve. The left eye had no perception of light and the right $6 / 5$ corrected acuity $\left(+0.50\right.$ cyl $\left.180^{\circ}\right)$. There was no refractive error in the left eye. He had normal colour vision tested with Ishihara plates and normal visual fields in the right eye. Both optic discs had a somewhat irregularly oval outline, and there was an anomalous arteriole in the superonasal quadrant of the atrophic left disc.

\section{Discussion}

Of several tumours affecting the anterior visual pathway in childhood gliomas and craniopharyngiomas are the most commonly encountered. ${ }^{10}$ Both of these tumours are thought to arise from developmental anomalies dating from embryonic life.

Craniopharyngiomas are benign tumours that arise very early in development from the blind-ended pouch described by Rathke ${ }^{11} 150$ years ago. Rathke's pouch appears on the 21st day of life and becomes a

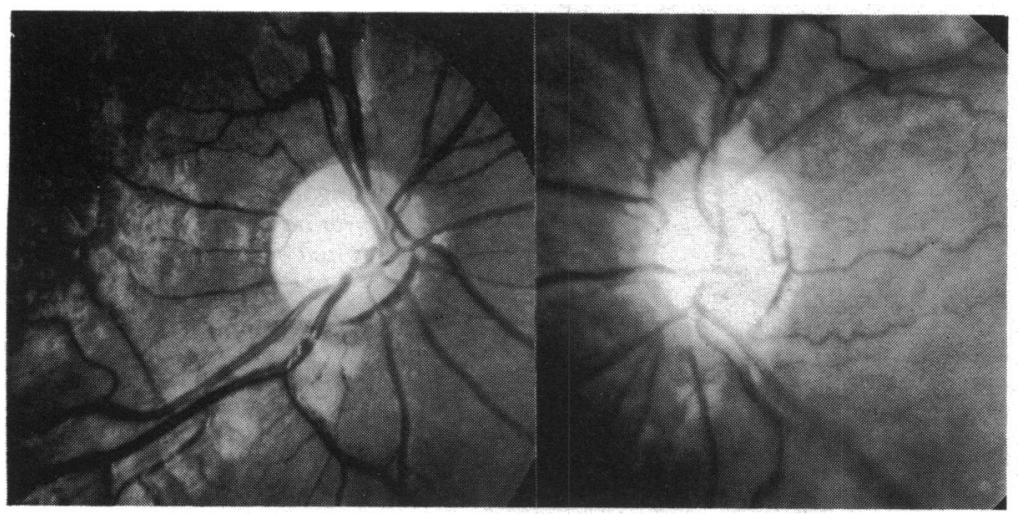

Fig. 7 Case 7. The fundi in June 1981. Both optic discs are irregularly oval in outline and the left optic disc is slightly smaller than the right. In addition the left optic disc shows an anomalous arteriole. The patient had a presumed optic glioma. 
blind-ended tube with its fundus near the developing diencephalon, chiasm, third ventricle, and neurohypophysis. The infundibulum or stalk becomes closed off by the 47 th day; there is evidence of this connection even in adult life in that craniopharyngiomas are found outside the hypophysis. Both the extrahypophyseal location of craniopharyngiomas and their adamantinomatoid structure generally argue in favour of their early embryological origin, ${ }^{12} \mathrm{a}$ view advanced by Erdheim ${ }^{13}$ in 1903 .

Hudson $^{14}$ originally indicated that optic nerve gliomas were benign, but there has been much discussion recently on the pathology of visual pathway gliomas. However, most authors believe that in childhood they lack malignant features ${ }^{15}$ or are a benign type of pilocytic astrocytoma. ${ }^{16}$ They generally behave in a benign manner on tissue culture. ${ }^{17}$ It has been proposed that they are a form of developmental abnormality or hamartoma.

There have been several recent summaries of the embryology of the eye, ${ }^{18-22}$ and its course in the first 2 months was detailed by $\mathrm{O}^{\prime}$ Rahilly, ${ }^{23}$ who examined 100 sectioned embryos whose development had been carefully staged.

Although crown-rump length (CRL) and gestational age (GA) are time-honoured and familiar in principle to most ophthalmologists, each of these measurements is subject to its own special imprecision. CRL is influenced greatly by the method of measurement, the extent of flexures, and the amount of shrinkage in preparation, and GA is as imprecise as the vagueness of the time of conception. Staging based on internal and external criteria, particularly in the early stage the number of somites, is frequently used as a more reproducible measurement. ${ }^{24}$ Originally known as developmental horizons, stages I-XXIII were described, stage I being the unicellular organism and stage XXIII heralding the end of embryonic development and the beginning of the fetal phase. By stage XXIII the fetus is well developed, with clearly defined organs, and the eyelids are nearly closed. $\mathrm{O}^{\prime} \mathrm{Rahilly}{ }^{25}$ has been responsible for staging development up to stage IX.

The first clear evidence of a precursor of the human eye is found in the 8 somite stage $\mathrm{X}$ embryo (GA approximately 22 days, CRL approximately $2 \cdot 2 \mathrm{~mm}$ ). The 2 primordia appear on either side of a notch in the anterior end of the neural tube. These thickenings in the neural tube are joined by a primitive chiasma, the torus opticus. In invertebrates there is evidence that there is cross-over of some fibres at this stage. ${ }^{26}$ The primordia became evaginated to form a pair of vesicles which contact the overlying ectoderm by stage XIII (GRL 4.5, GA 26). The retina becomes distinguishable by stage XIV, when there is a clear differentiation between the optic stalk and the cup which ultimately forms the eye; it is notched below (the fetal fissure) for the entry of vessels. The cup closes beginning at stage XVI and is well advanced by stage XVII (CLR 12, GA 40). By stage XIX nerve fibres from the ganglion cells are growing back down the stalk, which is also soon surrounded by a cellular sheath. The optic nerve fibres cross the chiasm and reach the brain by stage XXL, and they become well defined around the area behind the optic disc by stage XXIII, at which time the optic nerve is surrounded by a thick sheath.

Thus by stage XXIII the optic nerve has its full complement of retinal ganglion cell axons, a well defined optic disc with an opening in the sclera that is contiguous with the optic nerve sheath. This is a gestational age of about 50 days and a crown rump length of between 27 and $31 \mathrm{~mm}$. It is uncertain when the scleral opening in the optic canal attains its final form, but Duke-Elder and Cook ${ }^{27}$ imply that this has occurred by the fifth month of gestation. Substantial congenital anomalies of the outline of the optic disc will have occurred by that time at the latest.

The patients described in this series all had optic discs that were congenitally abnormal (dysplastic) either in size, outline, vascular arrangement, or a combination of these. The degree of abnormality was greater than the commonly found conus defects, and if a conus was present it was not the only defect in in these cases.

Patients 1, 4, and 6 had small optic discs that were abnormal in a way that has variously been known as a crescent, conus, diversion, or situs inversus; these abnormalities may be grouped and called tilted,${ }^{28}$ but they were also smaller than normal. They should be distinguished from the acquired disc abnormality that is commonly seen in myopia, ${ }^{29}$ although not infrequently they are myopic.

Mann $^{29}$ pointed out that if one excluded the common (usually acquired) temporal crescent, nearly $70 \%$ of crescents occur inferiorly in the disc, and that a further $12 \%$ occur inferonasally or inferotemporally. Mann suggested that this predominantly inferior portion of the crescent indicated an origin from an anomaly of closure of the fetal fissure, and she thought that it was due to a germinal failure of the retinal pigment epithelium to reach the site of junction of the optic stalk with the cup. Dorrell ${ }^{28}$ pointed out that the retinal opening at the optic nerve head was often circular and the outline of the scleral canal was contracted across one segment, giving rise to a $D$ shape. In many cases the whole disc was D shaped, and in other cases there appeared to be fewer nerve fibres in the retina adjacent to the crescent. These abnormalities are of prenatal origin. Dorrell suggested that many cases of tilted discs represented a form of segmental hypoplasia, and he pointed out the 
similarity between the double ring sign in optic disc hypoplasia and the appearance of the crescent.

The retina is first supplied by vessels that come through the fetal fissure during stage XIV, and the central artery and vein are clearly apparent by the third month of gestation. By the seventh to eighth month the hyaloid system has degenerated, leaving the barest remnants, and it seems likely that the pattern of the central retinal artery, vein, and their branches take their life-long pattern at this stage. Venous shunt vessels as seen in patient 2 are almost certainly acquired in postnatal life, whereas the arterial abnormalities in patient 7 are more likely to be abnormal at birth, and probably several months before that.

The optic discs of patients 3 and possibly 4 were frankly hypoplastic. The diagnosis of hypoplastic optic discs is very subjective, because there is no ready way of measuring the optic disc clinically or of estimating the number of optic nerve fibres entering the optic disc. If one accepts these limitations, careful observation of the optic disc and the retinal nerve fibre layer can allow a reasoned diagnosis of minimal optic disc hypoplasia to be made. ${ }^{30}$ Frisen and Holmegaard ${ }^{30}$ pointed out that symmetrical involvement makes diagnosis difficult, and they drew attention to other pitfalls in diagnosis such as the unreliability of the double ring sign. Although at the Hospital for Sick Children we have seen several other patients with optic gliomas or craniopharyngiomas who have lesser degrees of hypoplasia, they have not all been included in this series, though an example of a minimal abnormality is seen in case 5 .

Not only were the optic discs in case 3 small but one also had a figure of 8 outline. Although it was impossible to carry out a visual field examination in this child, it is likely that she had a bitemporal hemianopia and at the very least a suprasellar tumour. Both of this child's optic discs may be analogous to the optic disc with the temporal field defect in congenital homonymous hemianopia. ${ }^{31}$ The fibres destined to cross in the chiasm either failed to do so or crossed and then died back in prenatal life, leaving the intact fibres from the temporal retina to insert themselves into the upper and lower parts of the disc, the nasal and temporal parts of the disc failing to develop.

These findings should suggest to the clinician that, when he finds a visual defect in patients with dysplastic optic discs, he should pay careful attention to the visual field examination when the patient is old enough to perform it in detail, and that a CT scan may be indicated because the cause may be a congenital but progressive tumour with devastating, but preventable, consequences for the future wellbeing of his patient.
I am grateful to Mr Michael Sanders, FRCS, of the National Hospital. Queen Square, for permission to publish details of case 3, to $\mathrm{Mr}$ Rolfe Sennhenn and Mr Martin Johns for their photographic skills and kindness to the patients, and to Anna Taylor, who prepared the drafts and manuscript.

\section{References}

1 Duke-Elder S. System of Ophthalmology. Normal and Abnormal Development: Congenital Deformities. P. 671 Kimpton: London, 1964: 3 (2)

2 Riise D. The nasal fundus ectasia. Acta Ophthalmol (Kbh) (suppl) 1976; 126

3 Rucker CW. Bitemporal defects in the visual fields resulting from developmental anomalies of the optic discs. Arch Ophthalmol 1946; 35: 546-54.

4 Enokson P. Perimetry in neuro-ophthalmological diagnosis. Acta Ophthalmol (Kbh) 1965; 82 (suppl): 11-4.

5 Graham MV, Wakefield GJ. Bitemporal visual field defects associated with anomalies of the optic discs. $\mathrm{Br} J$ Ophthalmol 1973; 57: 317-4.

6 Keane JR. Suprasellar tumours and incidental optic disc anomalies. Arch Ophthalmol 1977; 95: 2180-3.

7 Young S, Walsh FB, Knox DL. The tilted disc syndrome. Am J Ophthalmol 1976; 82: 16-23.

8 Hollenhorst RW, Younge BR. Ocular manifestations produced by adenomas of the pituitary gland: analysis of 1000 cases. In: Kohler PO, Ross GT, eds. Diagnosis and Treatment of Pituitary Tumours. Amsterdam: Exerpta Medica, 1973: 53-64.

9 Taylor DSI, Eustace P. Presentation at III International Neuroopthalmology Meeting in Valbella, Switzerland. March 1980.

10 Taylor D. Chiasmal syndromes in childhood. In: Wybar KC, Taylor DSI, eds. Pediatric Ophthalmology-Current Aspects. New York: Dekker, 1982.

11 Rathke H. Über die Entstehung der Glandula pituitaria. Arch Anat Physiol Wissensch 1838; 482.

12 Pertuiset B. Craniopharyngiomas. In: Vinken PJ, Bruyn GW, eds. Handbook of Clinical Neurology. Amsterdam and Oxford: North Holland, 1975: 532.

13 Erdheim J. Zür Normalen und pathologischen Histologie der Glandula thyroidea, parathyroidea und Hypophysis. Beitr Pathol 1903; 33: 158-236.

14 Hudson AC. Primary tumours of the optic nerve. $R$ Lond Ophthalmol Hosp Rep 1912; 18: 317-23.

15 Anderson DR, Spencer WH. Ultrastructural and histochemical observations of optic nerve gliomas. Arch Ophthalmol 1970; 83: 324-35.

16 Russell DS, Rubinstein LJ. Pathology of Tumours of the Nervous System. 3rd ed. Baltimore: William and Wilkins, 1971: 119.

17 Martunza RL, Kornblith PL, Liszozak TM. Characteristics of human optic gliomas in tissue culture. J Neurosurg 1977; 46: 78-84.

18 Lemire R, Loeser J, Leech R, Alvord E. Normal and abnormal development of the human nervous system. The Optic System. New York: Harper Row, 1975: chapter 13: 196-205.

19 Hoyt WF. Correlative and functional anatomy of the optic chiasm. Clin Neurosurg 1969; 17: 189-207.

20 Mann I. Development of the Human Eye. London: Cambridge University Press, 1964.

21 Dejean C, Hervouét F, Leplat G. L'embryologie de l'oeil et sa tératologie. Paris: Masson 1958.

22 Barber AN, Ronstrom GN, Muelling RJ. Development of the anterior visual pathway: optic chiasm. Arch Ophthalmol 1954; 52: 447-53.

23 O'Rahilly $R$. The early development of the eye in staged human embryos. Contrib Embryol 1966; 38: 1-42.

24 Streeter GL. Developmental horizons in human embryos. Age groups $X I-X X I I I$. Embryology reprint Vol II. Washington DC: Carnegie Institute, Washington, 1951. 
25 O'Rahilly R. Developmental stages in human embryos. Part $A$. Embryos of the first three weeks. Stages 1 to 9. Washington DC: Carnegie Institute, Washington, 1973.

26 Jacobson M, Hirose G. Origin of the retina from both sides of the embryonic brain: a contribution to the problem of crossing at the optic chiasma. Science 1978; 202: 637-9.

27 Duke-Elder S, Cook C. System of Ophthalmology. Normal and abnormal development. Part I. Embryology. London: Kimpton, 1963: 3 (1): 163 .
28 Dorrell D. The tilted disc. Br J Ophthalmol 1978; 62: 16-20.

29 Mann I. Developmental Abnormalities of the Eye. London: British Medical Association, 1957: 101.

30 Frisen L, Holmegaard L. Spectrum of optic nerve hypoplasia. Br J Ophthalmol 1978; 62: 7-15.

31 Hoyt WF, Behrens MM, Rios-Montenegro EN, Eckelhoff RJ. Homonymous hemioptic hypoplasia. Br J Ophthalmol 1972; 56: $537-45$. 